\title{
Modelling of Mechanical Properties of Metal Plates with Polymer Coatings
}

\author{
M.O. Kaptakov \\ Moscow Aviation Institute (National Research University), Volokolamskoeshosse, 4, 125993, Moscow, Russia \\ mkaptakov@mail.ru
}

Article History: Received: 11 January 2021; Accepted: 27 February 2021; Published online: 5 April 2021

\begin{abstract}
In this work, we compare the experimental and calculated results obtained in the numerical simulation of uniaxial tension of specimens of metal plates with a thickness of $0.7 \mathrm{~mm}$. For modeling, the Digimat-FE (MSC) system was used, which in numerical calculations uses the finite element solver of the Marc software package (MSC). It is shown that for samples without coatings, the found theoretical values of the critical load quite well correspond to the points on the experimental diagrams at which the dependence of the load and displacement ceases to be linear. For specimens with coatings, the critical loads are significantly lower, and for their description it is necessary to obtain a refined estimate taking into account the effect of residual stresses.
\end{abstract}

Keywords: Coatings, mechanical properties, modeling, strength, stresses.

\section{Introduction}

On the basis of the known mechanical properties of coatings, their strength and durability can be assessed taking into account the action of external loads and taking into account the presence of residual stresses arising from the use of heat treatment during the coating process [1-9]. It is also possible to evaluate the effect of coatings on the mechanical behavior of protected thin-walled structures[10-14]. When carrying out strength calculations of large-sized structures, the effect of coatings can often be neglected if the wall thickness of the products significantly exceeds the thickness of the coatings and the rigidity of the coatings is much lower than the rigidity of the structure material[15-20]. However, it is obvious that if the thickness of the coating is comparable to the thickness of the structural element and if the coatings have sufficient rigidity, then their effect cannot be neglected under certain loading conditions[21-29]. On the other hand, coatings properties can be adjusted my the external mechanical action [30-41].

\section{Calculation of the mechanical properties of coated metal plates}

The effect of the coating in tensile tests is reduced to a decrease in the level of determined average stresses. The decrease occurs due to an increase in the calculated cross-sectional area of the coated sample. From the point of view of the bearing capacity of the samples, the effect of coatings is insignificant.This is confirmed by calculations. Fig. 1a shows a comparison of the experimental and calculated results obtained in the numerical simulation of uniaxial tension of specimens $0.7 \mathrm{~mm}$ thick (Fig.1b). For modeling, the Digimat-FE (MSC) system was used, which in numerical calculations uses the finite element solver of the Marc software package (MSC). As the initial data, the calculation included an experimental stress-strain diagram for a steel substrate and elastic characteristics of the coating: Poisson's ratio of 0.4 and Young's modulus equal to $1 \mathrm{GPa}, 3 \mathrm{GPa}$, or $6 \mathrm{GPa}$. In the calculations, a uniaxial stress state was specified with a stepwise increase in tensile deformations. At each step of the calculation, the system calculated the average stresses arising in the fragment and, thus, a stress-strain diagram was constructed, which was compared with the experimental data. The calculation was carried out up to $1 \%$ deformations at which the polymer coating material is deformed in the linear elastic zone and does not collapse. It was assumed that the deformations of the coating and substrate are compatible. The size of the simulated fragment of the plate was $1 \times 1 \mathrm{~cm}$. Figure 1a shows that the influence of the intrinsic elastic properties of the coatings is insignificant even for the thin samples considered in the calculations, the thickness of which exceeds the thickness of the coatings by only 7 times.

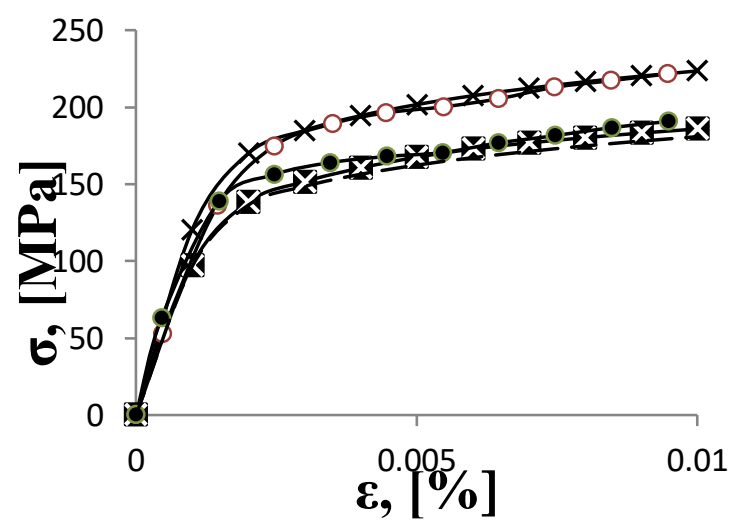


a
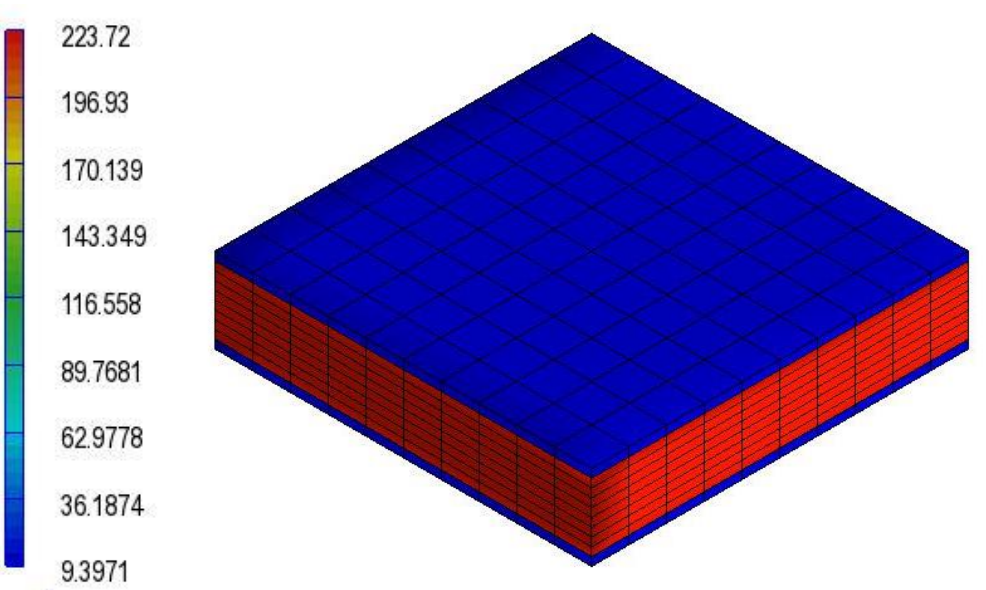

b

Fig. 1. Comparison of simulation results and experimental diagrams for the case of uniaxial tension of $0.7 \mathrm{~mm}$ thick specimens (a) and an example of finite element modeling of a representative fragment of a coated specimen (b). The color scale shows the level of maximum normal stresses found in the calculation at a given modulus of elasticity of the coating $3 \mathrm{GPa}$.

The results of testing plates for buckling in compression are shown in Fig. 1. Each diagram in these figures is obtained by averaging experimental data over five samples of the same type. The lower end of the samples was fixed motionless in the grip of the testing machine, and a compressive vertical load was applied to the upper end, also through rigid fixation in the grip. Therefore, in fact, in the experiment, the boundary conditions corresponding to the rigid pinching of the ends of the plates were realized. Fig. 1 shows the found dependences of the displacements of the upper ends of the samples (displacement of the cross arm of the testing machine) on the level of the applied compressive load. It can be seen that, under conditions of supercritical deformation, the diagrams of samples without coatings are significantly higher than those for samples with coatings. The difference in the behavior of the samples turns out to be minimal for the case of their greatest thickness and maximum for thin samples (Fig. 1a, b), which is natural.
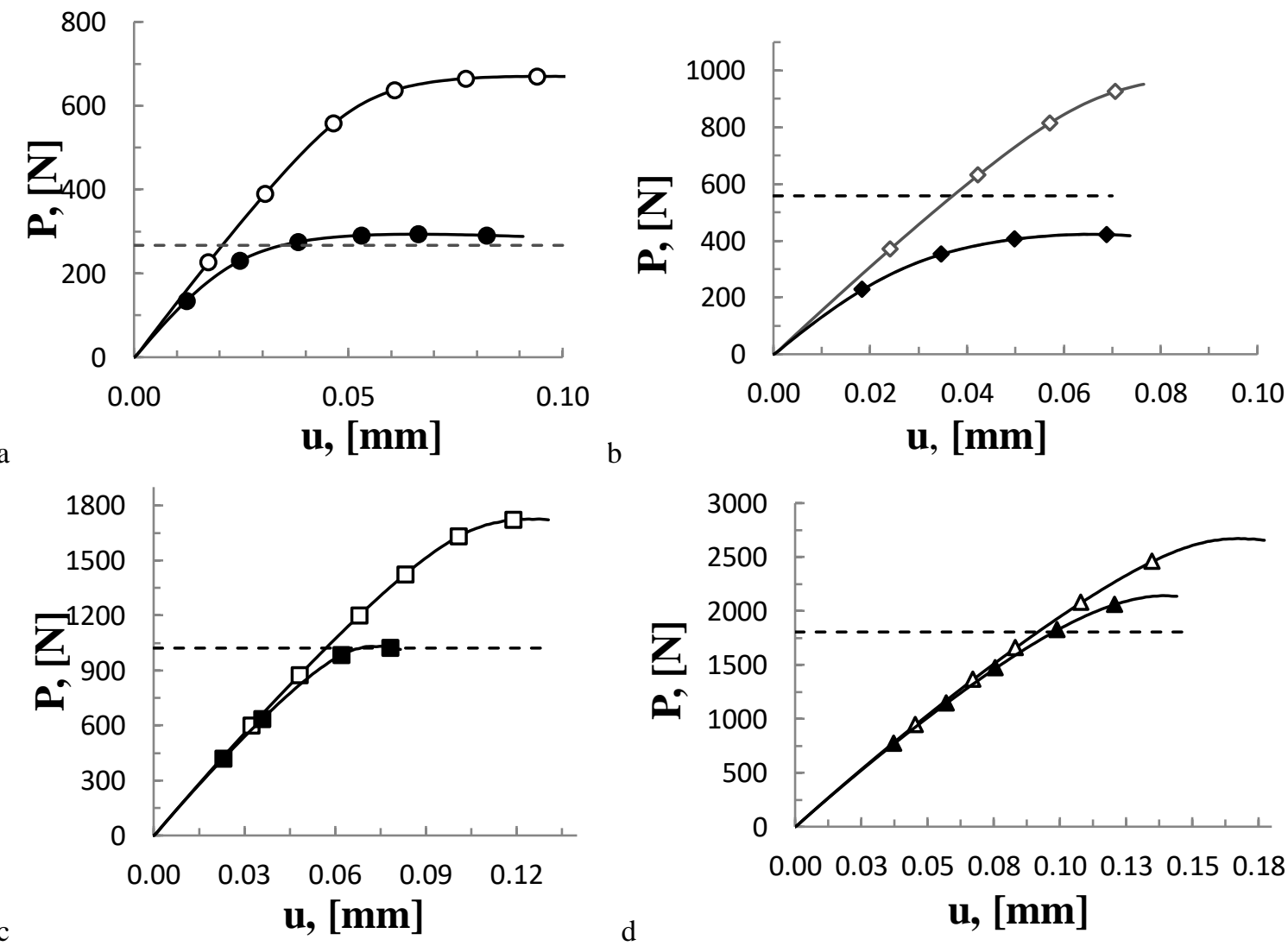
Fig. 2. Results of tests for buckling in compression. The designations are similar to those shown in Fig. 1. The dotted line shows the theoretical value of the critical load buckling.

The theoretical values of the critical load buckling in the graphs $P_{\kappa p}$ in Fig. 2 are marked with horizontal dashed lines. These values were found on the basis of the well-known formula from the theory of bar stability for the case of vertical load action and rigid pinching of the bar ends:

$P_{\kappa p}=\frac{4 \pi^{2} E J}{l^{2}}$,

where $l=86 \mathrm{~mm}$ - rod length, $E$ - Young's modulus, $J$-moment of inertia of the cross-section of the bar.

When modeling uncoated plates, we take $E=E_{c m}$ - Young's modulus of steel, $J=J_{c m}=b h^{3} / 12-$ moment of inertia of samples with thickness $h$ and width $b$. When modeling coated plates, the flexural stiffness of the corresponding bar should be calculated taking into account the additional contribution from the coating layers: $E J=2 E_{n} J_{n}+E_{c m} J_{c m}$, where $E_{n}$ - modulus of elasticity of the coating, $J_{n}$ - moment of inertia of coating layers, offset relative to the neutral line of the bar. However, the use of such a refined estimate leads to an insignificant change in the calculated critical load (within $2 \%$ ), which cannot explain the obtained experimental data. Therefore, in the graphs in Fig. 2 shows the only critical load value calculated without considering the effect of coatings.

Note that for samples without coatings, the found theoretical values of the critical load are in good agreement with the points on the experimental diagrams at which the dependence of the load and displacement ceases to be linear (see Fig. 2). For specimens with coatings, the critical loads turn out to be significantly lower, and to describe them, most likely, it is necessary to obtain an updated estimate taking into account the effect of residual stresses.

\section{Conclusions}

Thin-walled structural elements of aviation, space, automobile technology, which receive loads, are usually made with a thickness of more than $1 \mathrm{~mm}$. In this case, in static strength calculations, the effect of thin polymer coatings can be neglected. However, when assessing the supercritical behavior of structures with loss of stability, when performing nonlinear calculations, etc. neglecting the effect of coatings can lead to errors in the resulting predictions.

\section{References}

1. Bodryshev, V.V., Babaytsev, A.V., Rabinskiy, L.N. Investigation of processes of deformation of plastic materials with the help of digital image processing// PeriodicoTcheQuimica, 2019, 16(33), p. 865-876.

2. Astapov, A.N., Kuznetsova, E.L., Rabinskiy, L.N. Operating capacity of anti-oxidizing coating in hypersonic flows of air plasma//Surface Review and Letters, 2019, 26(2), 1850145 p.

3. Rabinskiy, L.N., Tushavina, O.V., Starovoitov, E.I. Study of thermal effects of electromagnetic radiation on the environment from space rocket activity // INCAS Bulletin, 2020, 12(Special Issue), p. 141-148.

4. Babaytsev, A.V., Orekhov, A.A., Rabinskiy, L.N. Properties and microstructure of AlSi10Mg samples obtained by selective laser melting// Nanoscience and Technology: An International Journal, 2020, 11(3), p. 213-222.

5. Kuznetsova, E.L., Rabinskiy, L.N. Heat transfer in nonlinear anisotropic growing bodies based on analytical solution // Asia Life Sciences, 2019, (2), p. 837-846.

6. Kuznetsova, E.L., Rabinskiy, L.N. Numerical modeling and software for determining the static and linkage parameters of growing bodies in the process of non-stationary additive heat and mass transfer//PeriodicoTcheQuimica, 2019, 16(33), p. 472-479.

7. Kuznetsova, E.L., Rabinskiy, L.N. Linearization of radiant heat fluxes in the mathematical modeling of growing bodies by the action of high temperatures in additive manufacturing //Asia Life Sciences, 2019, (2), p. 943-954.

8. Egorova, O.V., Kyaw, Y.K. Solution of inverse non-stationary boundary value problems of diffraction of plane pressure wave on convex surfaces based on analytical solution//Journal of Applied Engineering Science, 2020, 18(4), p. 676-680.

9. Formalev, V.F., Kolesnik, S.A., Selin, I.A. Local non-equilibrium heat transfer in an anisotropic halfspace affected by a non-steady state point heat source // Herald of the Bauman Moscow State Technical University, Series Natural Sciences. 2018. 80(5), p. 99-111.

10. Formalev, V.F., Kartashov, É.M., Kolesnik, S.A. On the Dynamics of Motion and Reflection of Temperature Solitons in Wave Heat Transfer in Limited Regions // Journal of Engineering Physics and Thermophysics, 2020, 93(1), p. 10-15.

11. Formalev, V.F., Bulychev, N.A., Kuznetsova, E.L., Kolesnik, S.A. The Thermal State of a Packet of Cooled Microrocket Gas-Dynamic Lasers // Technical Physics Letters, 2020, 46(3), p. 245-248. 
12. Rabinskiy, L.N., Tushavina, O.V., Formalev, V.F. Mathematical modeling of heat and mass transfer in shock layer on dimmed bodies at aerodynamic heating of aircraft// Asia Life Sciences, 2019, (2), p. 897911.

13. Antufev, B.A., Egorova, O.V., Rabinskiy, L.N. Quasi-static stability of a ribbed shell interacting with moving load// INCAS Bulletin, 2019, 11, p. 33-39.

14. Rabinsky, L.N., Kuznetsova, E.L. Simulation of residual thermal stresses in high-porous fibrous silicon nitride ceramics // Powder Metallurgy and Metal Ceramics, 2019, 57(11-12), p. 663-669.

15. Rabinskiy, L.N. Non-stationary problem of the plane oblique pressure wave diffraction on thin shell in the shape of parabolic cylinder// PeriodicoTcheQuimica, 2019, 16(32), p. 328-337.

16. Dobryanskiy, V.N., Rabinskiy, L.N., Tushavina, O.V. Experimental finding of fracture toughness characteristics and theoretical modeling of crack propagation processes in carbon fiber samples under conditions of additive production// PeriodicoTcheQuimica, 2019, 16(33), p. 325-336.

17. Kolesnik, S.A., Bulychev, N.A., Rabinskiy, L.N., Kazaryan, M.A. Mathematical modeling and experimental studies of thermal protection of composite materials under high-intensity effects of laser radiation// Proceedings of SPIE - The International Society for Optical Engineering. 2019. 11322, article number 113221R.

18. Babaytsev, A.V., Kuznetsova, E.L., Rabinskiy, L.N., Tushavina, O.V. Investigation of permanent strains in nanomodified composites after molding at elevated temperatures// PeriodicoTcheQuimica, 2020, 17(34), p. 1055-1067.

19. B.A. Garibyan. Mechanical Properties of Electroconductive Ceramics, International Journal of Pharmaceutical Research, 2020, Vol. 12, Supplementary Issue 2, pp. 1825-1828.

20. B.A. Garibyan. Enhancement of Mechanical Properties of Inorganic Glass under Ultrasonic Treatment, International Journal of Pharmaceutical Research, 2020, Vol. 12, Supplementary Issue 2, pp. 1829-1832.

21. O.A. Butusova. Surface Modification of Titanium Dioxide Microparticles Under Ultrasonic Treatment, International Journal of Pharmaceutical Research, 2020, Vol. 12, I. 4, pp. 2292-2296.

22. A.N. Tarasova. Vibration-based Method for Mechanochemical Coating Metallic Surfaces, International Journal of Pharmaceutical Research, 2020, Vol. 12, Supplementary Issue 2, pp. 1160-1168.

23. Bulychev, N.A., Rabinskiy, L.N. Ceramic nanostructures obtained by acoustoplasma technique//Nanoscience and Technology: An International Journal, 2019, 10(3), p. 279-286.

24. Anikin V.A., Vyshinsky V.V., Pashkov O.A., et al. Using the maximum pressure principle for verification of calculation of stationary subsonic flow. Herald of the Bauman Moscow State Technical University, Series Mechanical Engineering, 2019, no. 6, pp. 4-16.

25. Bulychev, N.A., Rabinskiy, L.N., Tushavina, O.V. Effect of intense mechanical vibration of ultrasonic frequency on thermal unstable low-temperature plasma// Nanoscience and Technology: An International Journal, 2020, 11(1), p. 15-21.

26. B.A. Garibyan. Modelling of Technical Parameters of Discharge Reactor for Polymer Treatment, International Journal of Pharmaceutical Research, 2020, Vol. 12, Supplementary Issue 2, pp. 1833-1837.

27. A.N. Tarasova. Effect of Reagent Concentrations on Equilibria in Water-Soluble Complexes, International Journal of Pharmaceutical Research, 2020, Vol. 12, Supplementary Issue 2, pp. 1169-1172.

28. A.N. Tarasova. Effect of Vibration on Physical Properties of Polymeric Latexes, International Journal of Pharmaceutical Research, 2020, Vol. 12, Supplementary Issue 2, pp. 1173-1180.

29. Yu.V. Ioni. Synthesis of Metal Oxide Nanoparticles and Formation of Nanostructured Layers on Surfaces under Ultrasonic Vibrations, International Journal of Pharmaceutical Research, 2020, Vol. 12, Issue 4, pp. 3432-3435.

30. O.A. Butusova. Vinyl Ether Copolymers as Stabilizers of Carbon Black Suspensions, International Journal of Pharmaceutical Research, 2020, Vol. 12, Supplementary Issue 2, pp. 1152-1155.

31. Yu.V. Ioni, A. Ethiraj. Study of Microparticles Surface Modification by Electrokinetic Potential Measuring, International Journal of Pharmaceutical Research, 2020, Vol. 12, Issue 4, pp. 3436-3439.

32. N.A. Bulychev, A.V. Ivanov. Study of Nanostructure of Polymer Adsorption Layers on the Particles Surface of Titanium Dioxide, International Journal of Nanotechnology, 2019, Vol. 16, Nos. 6/7/8/9/10, pp. $356-365$.

33. Yu.V. Ioni. Effect of Ultrasonic Treatment on Properties of Aqueous Dispersions of Inorganic and Organic Particles in Presence of Water-Soluble Polymers, International Journal of Pharmaceutical Research, 2020, Vol. 12, Issue 4, pp. 3440-3442.

34. O.A. Butusova. Stabilization of Carbon Microparticles by High-Molecular Surfactants, International Journal of Pharmaceutical Research, 2020, Vol. 12, Supplementary Issue 2, pp. 1147-1151.

35. Yu.V. Ioni, A. Ethiraj. New Tailor-Made Polymer Stabilizers for Aqueous Dispersions of Hydrophobic Carbon Nanoparticles, International Journal of Pharmaceutical Research, 2020, Vol. 12, Issue 4, pp. 3443-3446.

36. N.A. Bulychev, A.V. Ivanov. Effect of vibration on structure and properties of polymeric membranes, International Journal of Nanotechnology, 2019, Vol. 16, Nos. 6/7/8/9/10, pp. $334-343$. 
37. N.A. Bulychev, A.V. Ivanov. Nanostructure of Organic-Inorganic Composite Materials Based on Polymer Hydrogels, International Journal of Nanotechnology, 2019, Vol. 16, Nos. 6/7/8/9/10, pp. 344 355.

38. Yu.V. Ioni. Nanoparticles of noble metals on the surface of graphene flakes, PeriodicoTcheQuimica, 2020, Vol. 17, No. 36, pp. 1199-1211.

39. N.A. Bulychev, M.A. Kazaryan. Optical Properties of Zinc Oxide Nanoparticles Synthesized in Plasma Discharge in Liquid under Ultrasonic Cavitation, Proceedings of SPIE, 2019, Vol. 11322, article number 1132219.

40. Bulychev N. A., Kuznetsova E.L., Bodryshev V. V.Rabinskiy L.N. Nanotechnological aspects of temperature-dependent decomposition of polymer solutions, Nanoscience and Technology: An International Journal, 2018, Vol. 9 (2), p.91-97.

41. O.A. Butusova. Adsorption Behaviour of Ethylhydroxyethyl Cellulose on the Surface of Microparticles of Titanium and Ferrous Oxides, International Journal of Pharmaceutical Research, 2020, Vol. 12, Supplementary Issue 2, pp. 1156-1159. 